\title{
PROTÓTIPO DE APLICATIVO MULTIMÍdIA PARA A AQUISIÇÃO DE VOCABULÁRIO DE LÍNGUA INGLESA NA INFÂNCIA
}

\section{Prototype of Multimedia app for English Vocabulary Acquisition in Childhood}

\author{
Vivian Nádia Ribeiro de Moraes Caruzzo ${ }^{1}$ \\ Francisco Rolfsen Belda ${ }^{2}$ \\ Jackson Gomes Soares Souza ${ }^{3}$ \\ Sara Veloso Lara ${ }^{4}$ \\ Claudio Noel de Toni Junior 5
}

\begin{abstract}
Resumo: O rápido desenvolvimento das Tecnologias Digitais de Informação e Comunicação impulsiona o desenvolvimento de produtos educativos e educacionais em meio digital na forma de softwares e aplicativos para aparelhos móveis. No cenário tecnológico atual ainda mantém-se, contudo, a importância e o valor dos recursos educacionais impressos, e especialmente dos livros didáticos, como instrumentos de aquisição de vocabulário por crianças em fase de alfabetização, abrindo novas oportunidades para a criação de produtos educacionais híbridos, que combinem recursos característicos das plataformas digitais e dos livros em papel. Nesse sentido, o presente trabalho relata e discute resultados do desenvolvimento experimental de um protótipo de aplicativo multimodal para a aquisição lexical de inglês por crianças de sete a dez anos. O planejamento e a construção do protótipo se deram no âmbito de uma disciplina do Programa de Pós-Graduação em Educação Escolar da FCLAr/UNESP. É apresentada uma proposta para o desenho das telas do aplicativo, enquanto interface visual a ser usada pelo público da educação infantil, e demonstrada sua lógica de navegação por meio de fluxogramas, de modo a orientar a futura implementação desses recursos por equipes de desenvolvimento. Por fim, são discutidos resultados de um questionário semiestruturado respondido por dois grupos de professores de língua inglesa que
\end{abstract}

\footnotetext{
${ }^{1}$ Mestra e Doutoranda em Linguística e Língua Portuguesa Faculdade Portuguesa Faculdade de Ciências e Letras - Campus de Araraquara (UNESP). https://orcid.org/0000-0002-1022-6885 vivian.moraes@unesp.br

${ }^{2}$ Doutor em Engenharia de Produção pela Universidade de São Paulo (USP). Professor do Departamento de Comunicação Social da Faculdade de Arquitetura, Artes e Comunicação - Campus de Bauru (UNESP). https://orcid.org/0000-0001-6350-7026. E-mail: belda@faac.unesp.br.
}

\footnotetext{
${ }^{3}$ Mestre em Gestão e Tecnologia em Sistemas Produtivos e Doutorando no Programa de Pós-Graduação em Educação Escolar da Faculdade de Ciências e Letras - Campus de Araraquara (UNESP). Professor de Graduação em Ensino, Análise e Desenvolvimento de Sistemas no Instituto Federal de São Paulo (IFSP). https://orcid.org/0000-0003-4952-8618 E-mail: jackson.gomes@gmail.com.
}

\footnotetext{
${ }^{4}$ Mestra em Estudos Linguísticos e Literários em Inglês pela Faculdade de Filosofia, Letras e Ciências Humanas (FFLCH - USP). Doutoranda no Programa de Pós-Graduação em Linguística e Língua Portuguesa da Faculdade de Ciências e Letras - Campus de Araraquara (UNESP). https://orcid.org/0000-0003-3180-3941. E-mail: veloso2005@yahoo.com.br.

${ }^{5}$ Doutor em Geografia pelo Instituto de Geociências e Ciências Exatas - Campus de Rio Claro (UNESP). Mestrando no Programa de Pós-Graduação em Educação Sexual da Faculdade de Ciências e Letras - Campus de Araraquara (UNESP). https://orcid.org/0000-0001-5374-8475. E-mail: juniortoni100@gmail.com.
} 
refletiram sobre as condições, as possibilidades e os limites para uma efetiva aplicação do produto em contextos de educação formal e não-formal.

Palavras-chave: Produto educacional. Protótipo. Aquisição de vocabulário.

\begin{abstract}
The rapid development of Information and Communication Technologies has boosted the development of educational products in digital media in the form of softwares and applications for mobile devices. In the current technological scenario, however, the importance and value of printed educational resources, and especially of textbooks, remain as instruments for the acquisition of vocabulary by children in the stages of literacy, creating new opportunities for the design of hybrid educational products, which combine distinctive features of digital platforms and paper books. In this sense, this paper reports and discusses results of the experimental development of a prototype for a multimodal application for the lexical acquisition of English by children aged seven to ten years old. The planning and development of the prototype took place within the scope of a subject of the Graduate Program in School Education at FCLAr / UNESP. A proposal for the design of the application screens is presented, as a visual interface to be used by the childhood education audience, and its navigation logic is demonstrated through flowcharts, in order to guide the future implementation of these resources by development teams. Finally, results of a semi-structured questionnaire answered by two groups of Brazilian English teachers are discussed regarding their reflection on the conditions, possibilities and limits for an effective application of the product in formal and non-formal education contexts.
\end{abstract}

Keywords: Educational product. Prototype. Vocabulary Acquisition.

\title{
1 Introdução
}

Nas últimas três décadas, as Tecnologias Digitais da Informação e Comunicação (TDIC) vêm promovendo novas formas de produzir, difundir e mediar conhecimentos em diversos domínios sociais, inclusive no campo da educação. Elas compreendem ferramentas multimodais de comunicação que sincretizam diferentes linguagens - verbal, visual, gestual, sonora e imagética, por exemplo — e, com isso, reconfiguram gêneros discursivos. Sua inserção em contextos educacionais provoca mudanças profundas nos modos de ensino e de aprendizagem, demandando de professores e aprendizes novas habilidades e competências aplicadas não apenas ao uso, mas também ao próprio desenvolvimento de recursos didáticos e paradidáticos utilizados em apoio aos processos da educação.

No campo educacional, os aplicativos para dispositivos móveis (como telefones e tablets) com acesso à internet constituem uma modalidade emergente aplicada ao ensino de língua estrangeira. Eles são softwares simples, geralmente com uma finalidade específica, que possibilitam uma aprendizagem mais lúdica, capaz de engajar estudantes e prover feedback instantâneo sobre sua experiência de utilização e aquisição de conhecimentos. Para além disso, promovem maior autonomia do aprendiz, que além de consumidor pode ser também, em determinadas circunstâncias, criador de seu próprio conteúdo.

Nesse contexto, o presente artigo relata e discute um estudo de natureza descritivo-exploratória associado ao processo de elaboração de um protótipo original de aplicativo educacional chamado VocAppulary, voltado para a aprendizagem de vocabulário em língua inglesa para crianças na fase final de alfabetização, a ser usado de modo combinado a um livro paradidático impresso. Nessa fase, idealmente, as crianças já estão letradas em sua língua materna e também, parcialmente, em uma língua estrangeira. Acredita-se que, ao 
sincretizar as dimensões da forma (oral e escrita) e do significado vocabular com apoio de imagens, áudio e vídeo, numa experiência transmídia, esse tipo de recurso possa tornar tal aprendizagem ainda mais rica e atraente.

Existem vários aplicativos educacionais que focam na aquisição lexical provenientes das principais plataformas como web, App Store e Google Play. Embora apresentem, em sua maioria, um rico banco de imagens associadas à forma verbal escrita dos vocábulos e seus significados, eles em geral não estão associados a algum tipo de material físico, como livros ou apostilas. $\mathrm{O}$ aplicativo proposto e descrito neste trabalho apresenta esse diferencial, incluindo um sistema de leitura de código QR por meio do qual o usuário pode usar a câmera de seu dispositivo móvel para acessar, a partir do livro impresso, uma interface digital que exibe imagens e reproduz conteúdos audiovisuais associados ao vocabulário aprendido. Assim, o aplicativo pode servir como material complementar de apoio didático ou mesmo para fins de entretenimento educacional, promovendo novas formas de ler, falar, escrever e ouvir em língua inglesa.

Ao longo deste texto, discutiremos as etapas processuais que abarcam a ideação e o desenvolvimento do protótipo. Apresentaremos as ferramentas de editoração e design digital utilizadas em cada estágio de elaboração do trabalho, imagens que revelam as telas do aplicativo, além da avaliação do protótipo por professores de inglês como língua estrangeira. Porém, é imperativo salientar que, embora destaquemos, em nossa proposta, o uso do aplicativo VocAppulary aliado a um livro paradidático, o material impresso não foi desenvolvido pela equipe de autores. Portanto, as discussões do presente artigo focalizarão o produto digital, enquanto o material impresso é mencionado a nível conceitual.

\section{Fundamentação da proposta}

\subsection{Aplicações digitais, suas características e recursos para o letramento}

As aplicações das TDIC têm expandido os modos de produzir, ler e compreender os textos e seus significados para além das formas tradicionalmente adotadas em práticas escolares, corporativas e familiares. Nos meios digitais, se tornaram multissemióticos, multimodais e hipermidiáticos (LEMKE,1998) e seu processamento e comunicação também ganharam dinamismo e instantaneidade inéditas.

Para Beaudouin (2002), o texto eletrônico modificou a relação entre leitura e escrita, entre autor e leitor. Seus novos papéis superam as funções específicas de produção e recepção e se estabelece entre eles uma relação de colaboração e coparticipação na construção dos conteúdos, tendo a internet como suporte para sua elaboração e circulação.

Num primeiro momento, essa tendência estimulou novas competências e habilidades para o uso da linguagem em contextos multimidiáticos e hipermidiáticos, mas tendo ainda na escrita a modalidade principal do processo de comunicação (ROJO, 2007). Mais recentemente, porém, os textos hipermidiáticos passaram a ser incrementados pela combinação de figuras e animações ao texto escrito, num processo de hibridização da forma e de ressignificação de conteúdos. Textos que eram até então bidimensionais se tornam multimodais, compostos por imagens, sons e movimento a ocupar o espaço virtual (LEFFA; CASTRO-VETROMILLE, 2008).

Nesse contexto, surgem os aplicativos para dispositivos móveis. Dentre suas características e aplicações pedagógicas, que podem contribuir para o aprendizado e letramento infantil, Almeida Júnior e Oliveira (2017) destacam-se, por exemplo: (a) teclado de fácil visualização e possibilidade de diferenciação entre letras maiúsculas, minúsculas, cursivas ou em bastão; (b) extensa galeria de imagens, geralmente associadas à linguagem verbal, o que auxilia a fixação do conteúdo na memória de longo prazo; (c) otimização dos 
espaços na tela, de modo a evitar distração do aprendiz com elementos desnecessários; (d) carregamento de jogos que favorecem a absorção do conteúdo de forma lúdica, estimulam a memória e a coordenação da competência motora dos aprendizes; e (e) recurso sintetizador de voz, que contribui para o aprimoramento fonológico da pronúncia de palavras, o que é especialmente útil para o ensino de uma segunda língua.

\subsection{Aprendizagem de segunda língua na infância}

Krashen (1982) é um dos principais autores a corroborar a ideia de que aprender uma segunda língua é mais fácil durante a infância do que na adolescência ou na fase adulta do desenvolvimento humano. Segundo ele, isso ocorre porque, durante a infância, o sistema cognitivo dos humanos está especialmente apto a receber inputs diversos e o cérebro pode ser comparado a uma esponja, processando tudo o que estiver à vista. Sendo assim a criança na fase inicial de alfabetização apresenta mais facilidade em adquirir um montante maior de palavras e aprendê-las até a idade do desenvolvimento crítico, aos doze anos, quando comparado a adolescentes e adultos.

Um estudo com crianças em desenvolvimento normal de linguagem, de Bassano, Maillochon e Eme (1998), constatou a existência de variações individuais nos primeiros estágios do desenvolvimento lexical em crianças, com relação ao número de palavras adquiridas em cada idade. Assim, as crianças apresentam uma fase inicial de aquisição lexical lenta, seguida de uma fase rápida, durante a qual muitas palavras são incorporadas diariamente; entretanto, segundo esses autores, há certa variação individual em relação à velocidade de aquisição. O mesmo estudo evidenciou que as crianças têm maior facilidade em adquirir e aprender palavras referentes a objetos do que a ações, por demandar operações cognitivas menos complexas.

Leventhal, Zajdenwerg e Silvério (2007, p. 18) apontam que crianças entre os sete e os dez anos de idade "estão em processo final de alfabetização e aptas à leitura em uma segunda língua". Assim, aos dez anos, elas geralmente estão alfabetizadas na língua materna e já o podem ser também parcialmente em uma segunda língua, conseguindo se expressar de maneira simples, tanto oralmente como na forma escrita da segunda língua.

Segundo Schütz (2003), o fato de que crianças até os dez anos de idade assimilam de forma equânime a língua materna e uma segunda língua se deve ao fato de estarem ainda no início de seu desenvolvimento cognitivo, com suas operações neurais menos consolidadas e seus hábitos linguísticos menos enraizados, o que as possibilita expandir a habilidade de compreensão e produção lexical, fonológica e morfossintática e, portanto, a adquirir um sistema enriquecido por fonemas de línguas estrangeiras. Ainda de acordo com o autor, a partir dos doze anos, as crianças entram na fase da puberdade e começam a apresentar maior dificuldade de assimilação, pois sua língua materna está então quase totalmente consolidada, tornando mais árduo o processo de construção de uma segunda língua.

O autor aponta, ademais, que crianças até dez anos não têm ainda seu desenvolvimento cognitivo completamente consolidado e, por isso, apresentam maior dificuldade para lidar com conceitos abstratos e hipotéticos, necessitando de experiências concretas e de uma percepção direta dos fenômenos referidos pela linguagem, o que se materializa através das práticas tradicionais de letramento, geralmente com uso de papel e lápis, e que podem também ser complementadas pela linguagem multimodal e multissemiótica dos aplicativos (SCHUTZ, 2003).

Essa hipótese também é corroborada por uma pesquisa fonoaudióloga experimental realizada sobre casos de bilinguismo precoce, com foco em crianças de dois a quatro anos de idade (PALALAS, 2011). Constatou-se, no caso estudado, que o léxico e a semântica se desenvolveram na mesma medida em ambas as línguas quando a criança esteve envolvida em 
atividades lúdicas que envolviam brinquedos e figuras de seu interesse por meio de recursos próprios dos aplicativos para dispositivos móveis, considerados especialmente úteis na promoção de uma aprendizagem mais interativa do vocabulário.

\section{Metodologia}

A experiência coletiva de pesquisa que motivou a realização deste trabalho teve abordagem qualitativa e pode ser classificada como exploratória e descritiva, orientada à geração de resultados empíricos capazes de subsidiar a proposição de novas perspectivas teóricas acerca do tema estudado (SAMPIERI; COLLADO; LUCIO, 2006).

O trabalho foi dividido em quatro etapas metodológicas: (a) revisão de produtos educacionais similares ao da proposta, disponíveis em lojas virtuais de aplicativos; (b) exercícios de aplicação com ferramentas e recursos de mídia digitais para o design de produtos educacionais; (c) prototipagem de um produto original de mídia digital capaz de facilitar a aquisição de língua estrangeira na infância; e (d) avaliação sobre a aplicabilidade da proposta e do protótipo por educadores com experiência no ensino de língua inglesa.

A proposta de desenvolvimento do protótipo de produto educacional se deu ao longo do segundo semestre de 2019, no âmbito de uma disciplina do Programa de Pós-Graduação em Educação Escolar (PPGEdu) na Faculdade de Ciências e Letras de Araraquara da Universidade Estadual Paulista Júlio de Mesquita Filho (UNESP).

A iniciativa possibilitou a aplicação de conceitos e práticas interdisciplinares por estudantes e pesquisadores com formações diversas, incluindo as áreas de letras e linguística, ciência da computação e educação. Foram abordadas técnicas de modelagem e prototipagem de objetos de aprendizagem e de produtos midiáticos digitais para aplicação educacional, incluindo a demonstração e experimentação sobre o uso de software e outros dispositivos, além da criação de interfaces e de propostas de arquitetura da informação e de fluxos de navegação com vistas ao desenvolvimento de aplicativos. Nas etapas de experimentação e prototipagem, foram utilizadas ferramentas de editoração e design digital de baixa ou média complexidade, como Google Drawings, Draw.io, Adobe Photoshop e Quant-UX.

Para a coleta de dados referentes à avaliação da aplicabilidade do produto, um questionário semiestruturado, com questões abertas e fechadas (VIEIRA-ABRAHÃO, 2006), foi aplicado e respondido por dois grupos de professores de inglês de duas escolas de idiomas na cidade de Araraquara, entre o final de fevereiro e o início de março de 2020. Os resultados dessa avaliação foram analisados e discutidos à luz de conceitos e de hipóteses previstas na literatura consultada acerca do uso de recursos digitais para a aquisição de vocabulário em língua estrangeira, bem como sobre seus usos potenciais para a educação de modo geral.

\section{Resultados do desenvolvimento do protótipo}

Nesta seção, serão apresentados, exemplificados e discutidos o percurso trilhado e os resultados alcançados com o desenvolvimento e avaliação do protótipo do aplicativo VocAppulary, conforme etapas, instrumentos e atividades sistematizadas no Quadro 1.

Quadro 1 - Etapas de desenvolvimento de atividades para a prototipagem do produto educacional

\begin{tabular}{|c|c|c|}
\hline Etapa & Instrumento/plataforma & Atividade Realizada \\
\hline Revisão de aplicativos & $\begin{array}{l}\text { Apple Store, Play Store, } \\
\text { Portal do Professor }\end{array}$ & $\begin{array}{l}\text { Mapeamento e análise inicial das características de produtos e recursos } \\
\text { educacionais correlatos disponíveis em lojas e repositórios virtuais }\end{array}$ \\
\hline Exercícios de design digital & Google Drawings & $\begin{array}{c}\text { Experimentação livre de design de telas para interface visual de aplicativos } \\
\text { e criação de fluxogramas sobre sua arquitetura de informação }\end{array}$ \\
\hline Planejamento do produto & Google Docs & $\begin{array}{l}\text { Relatório de apresentação do produto educacional idealizado, sua proposta } \\
\text { pedagógica, fundamentação teórica, público-alvo e distribuição }\end{array}$ \\
\hline
\end{tabular}




\begin{tabular}{|c|c|c|}
\hline $\begin{array}{c}\text { Desenvolvimento do } \\
\text { protótipo }\end{array}$ & $\begin{array}{c}\text { Quant-UX } \\
\text { Draw.io } \\
\text { Google Drawings } \\
\text { Adobe Photoshop }\end{array}$ & $\begin{array}{c}\text { Elaboração da identidade visual do aplicativo proposto, de um conjunto } \\
\text { inicial de telas para sua interface visual, fluxograma detalhado sobre sua } \\
\text { lógica de navegação e demais componentes }\end{array}$ \\
\hline Avaliação de aplicabilidade & Google Forms & $\begin{array}{c}\text { Elaboração e avaliação de resultados de um questionário submetido a } \\
\text { professores de língua inglesa acerca de suas impressões pedagógicas sobre } \\
\text { a proposta e da aplicabilidade do protótipo em determinados contextos } \\
\text { educacionais }\end{array}$ \\
\hline
\end{tabular}

Fonte: Elaborado pelos autores, 2020

\subsection{Experimentação, planejamento e desenvolvimento do protótipo}

Após a realização de uma revisão panorâmica sobre produtos e recursos correlatos ao produto idealizado para este trabalho, o grupo envolvido elaborou um exercício exploratório sobre técnicas de design digital orientadas a modelar a experiência de crianças da faixa etária visada, na condição de usuários de aplicativos educacionais acessados por dispositivos móveis, incluindo um fluxograma representativo de sua arquitetura de informação. Um exemplo do resultado dessa etapa pode ser visualizado na Figura 1. Com esse exercício, foi possível testar técnicas, reconhecer recursos básicos da ferramenta utilizada e extrair referências e inspirações para o desenvolvimento do protótipo.

Figura 1 - Exercícios de design digital: reprodução de tela de trabalho no Google Drawings

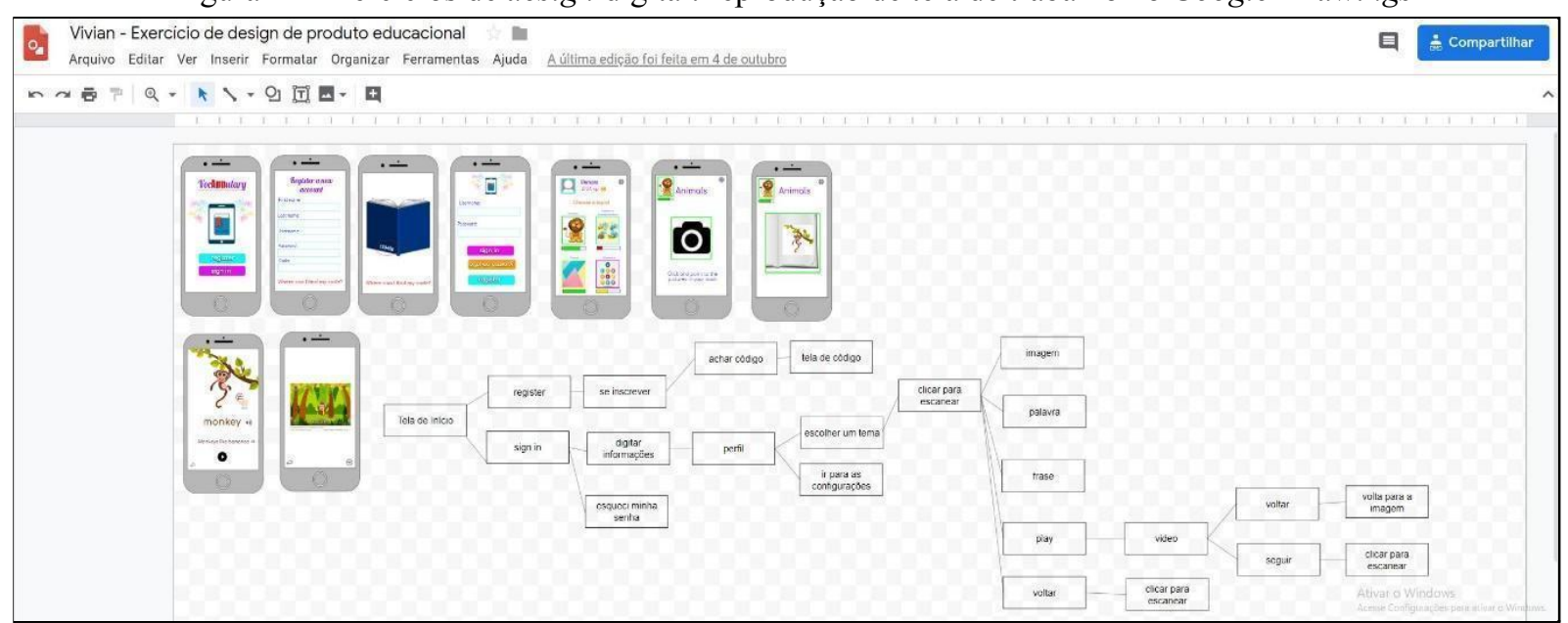

Fonte: Elaborado pelos autores, 2019.

A etapa seguinte teve por foco a elaboração da proposta pedagógica do aplicativo VocAppulary enquanto produto educacional e o planejamento de seu protótipo. Para orientar essas atividades, foi utilizado um roteiro de perguntas que abordou, por exemplo, a motivação educacional para a concepção do produto, seu público-alvo e propósito didático-pedagógico, as teorias que dariam suporte à proposta, as premissas sobre sua possível utilização em contextos de educação formal e não-formal, além de elementos práticos visando o processo de desenvolvimento do protótipo.

Decidiu-se, com isso, pela ideação de um aplicativo educacional multimodal e multimidiático que estivesse diretamente associado ao uso de um livro impresso paradidático voltado à aquisição de vocabulário de língua inglesa por crianças em fase de alfabetização. $\mathrm{O}$ público-alvo seria de crianças com idades entre sete e dez anos, independentemente de sua língua materna, permitindo, assim, que o projeto tivesse potencial de distribuição em âmbito internacional.

O desenvolvimento do protótipo desse produto teve início com a escolha do nome e criação de sua logomarca. O nome VocAppulary advém da junção de dois vocábulos em língua inglesa: vocabulary (vocabulário) e app, forma reduzida de application (aplicativo). $\mathrm{O}$ 
conceito por detrás do neologismo remete à finalidade do produto: a aquisição de vocabulário em inglês através do uso do aplicativo. Sua pronúncia (/ vou'kæp yə,leri /) é intencionalmente muito semelhante à palavra original vocabulary (/ voð'kæb yə,lcr i /), tendo esses aspectos fonéticos e fonológicos sido decisivos para a escolha do nome.

A imagem criada para representar o aplicativo é composta por um livro aberto na direção contrária de quem olha e um celular smartphone voltado para esse livro, de modo a ilustrar o funcionamento do produto, que combina o livro físico e o aplicativo a partir de um sistema de remissão com a leitura de códigos QR inseridos nas páginas impressas. A imagem de um rosto com expressão alegre foi sobreposta ao celular de modo a gerar identificação com o público infantil. As cores principais escolhidas para a logomarca foram azul e vermelho, em alusão às bandeiras do Reino Unido e dos Estados Unidos da América, principais comunidades anglófonas no mundo.

A partir dessa identidade visual, seguiu-se a criação da interface de uso e o desenho das telas do aplicativo. Os primeiros rascunhos foram feitos com uso do Google Drawings e as versões definitivas foram elaboradas com o software Quant-UX, com o apoio de tutoriais disponibilizados em blogs e canais de vídeos especializados. Essa plataforma de prototipagem oferece recursos próprios para o desenvolvimento de interfaces de aplicações digitais, tais como wireframe, bootstrap, icons, buttons, entre outros, incluindo o uso de $Q R$ code.

Figura 3 - Print da tela do projeto de prototipagem do VocAppulary na plataforma Quant-UX

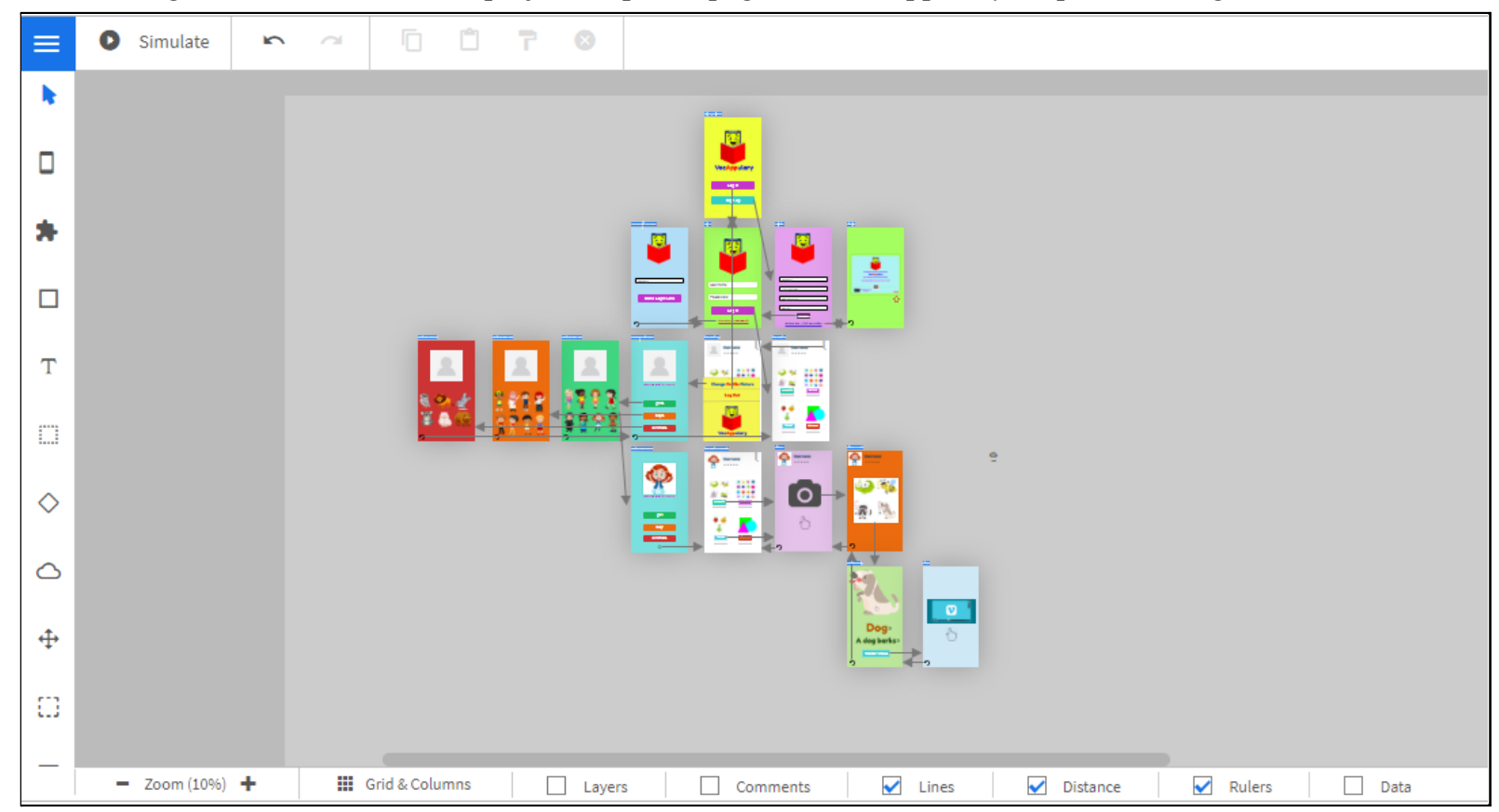

Fonte: Elaborado pelos autores, 2019.

Ao todo, foram criadas 17 telas para ilustrar a proposta e simular, em condições dinâmicas, o funcionamento básico do aplicativo e seus fluxos principais de navegação ${ }^{6}$. Em geral, as telas são coloridas e chamativas. Todos os elementos textuais presentes no aplicativo estão escritos em língua inglesa, de modo a atender um público amplo, internacional. Não há, portanto, opção de seleção de idiomas.

\footnotetext{
${ }^{6} \mathrm{O}$ conjunto geral das telas e uma simulação do protótipo de aplicativo podem ser acessados através do link https://www.quant-ux.com/\#/test.html?h=a2aa10aYNXGn5tnTCfdkQuVDDzSSeLgiYRyQ0eoyFK66ZOuzmcO vvt0D87jK
} 
$\mathrm{Na}$ tela inicial do protótipo, o usuário tem duas opções: fazer o login, caso já esteja registrado no aplicativo, ou o sign-up, caso seja seu primeiro acesso e queira registrar outro usuário, além da opção de recuperação de senha via e-mail (forgot your password?). Para o login, o usuário deverá atribuir-se um nome de usuário (username) e senha (password). Para registrar-se ao primeiro acesso, o usuário deve informar seu endereço de e-mail, nome de usuário (username), senha (password) e um código (code) presente na contracapa (ou quarta capa) do livro impresso. Para o usuário que não souber onde se encontra o código a ser digitado na área exigida, foi criado um link (where can I find my code?) que o encaminhará para outra tela específica de orientação ${ }^{7}$.

Após o login do usuário, apresenta-se a tela principal de aplicativo, que exibe seus recursos e funcionalidades principais, conforme ilustra a Figura 4. Encontram-se ali quatro categorias de vocabulário, correspondentes a campos semânticos alusivos a animais, cores, frutas e formatos (animals, colors, fruits e shapes) ${ }^{8}$. Abaixo de cada categoria e do nome de usuário (username), há ícones com cinco estrelas a serem automaticamente preenchidas (coloridas) de acordo com o avanço do usuário na realização das respectivas atividades, servindo como métrica para o acompanhamento de seu progresso até a conclusão de atividades propostas.

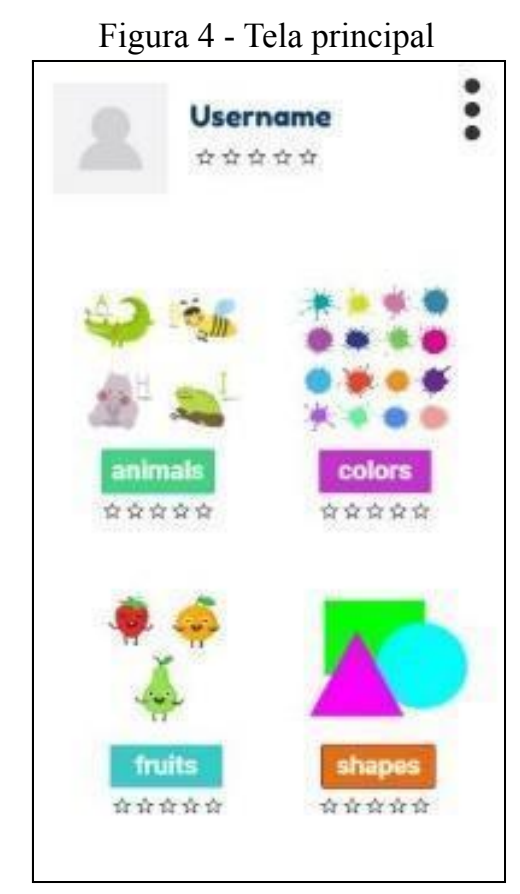

Fonte: Elaborado pelos autores, 2019.

\footnotetext{
${ }^{7}$ Ainda que o aplicativo pressuponha a existência de um livro físico, este recurso impresso não chegou a ser desenvolvido pelo grupo durante o trabalho de prototipagem.

${ }^{8}$ As imagens que ilustram esta tela são provenientes do repositório de uso gratuito www.freepik.com, com os seguintes endereços de creditação: Animais categoria: <a

href="https://br.freepik.com/fotos-vetores-gratis/fundo">Fundo vetor criado por rawpixel.com -

br.freepik.com</a $>$ Animais perfil: $<$ a href="https://br.freepik.com/fotos-vetores-gratis/fundo" $>$ Fundo vetor criado por brgfx - br.freepik.com $</ a>$ Crianças: $<\mathrm{a}$

href="https://br.freepik.com/fotos-vetores-gratis/fundo">Fundo vetor criado por brgfx - br.freepik.com $</ a>$

Cores: < a href="https://www.freepik.com/free-photos-vectors/hand">Hand vector created by milano83 Frutas:

$<$ a href="https://br.freepik.com/fotos-vetores-gratis/alimento">Alimento vetor criado por freepik -

br.freepik.com $</ a>$
} 
Ao clicar nas três pequenas esferas no canto superior direito desta tela, uma aba de funções é aberta e o usuário pode realizar logout ou optar por mudar a imagem de seu perfil (change profile picture), com a possibilidade de escolher um avatar conforme os gêneros masculino (boys), feminino (girls) ou neutro, neste caso representado pela categoria animais (animals). Os avatares sugeridos possuem características físicas e vestimentas representativas de raças e etnias distintas, como pode ser observado na Figura 5, que ilustra a categoria girls. Uma preocupação da equipe foi disponibilizar também uma categoria de imagens de gênero neutro para crianças que não se identificam com os gêneros binários. É relevante destacar que optamos por não disponibilizar a opção de upload de imagem para o perfil, uma vez que nosso público-alvo é composto por crianças menores de idade.

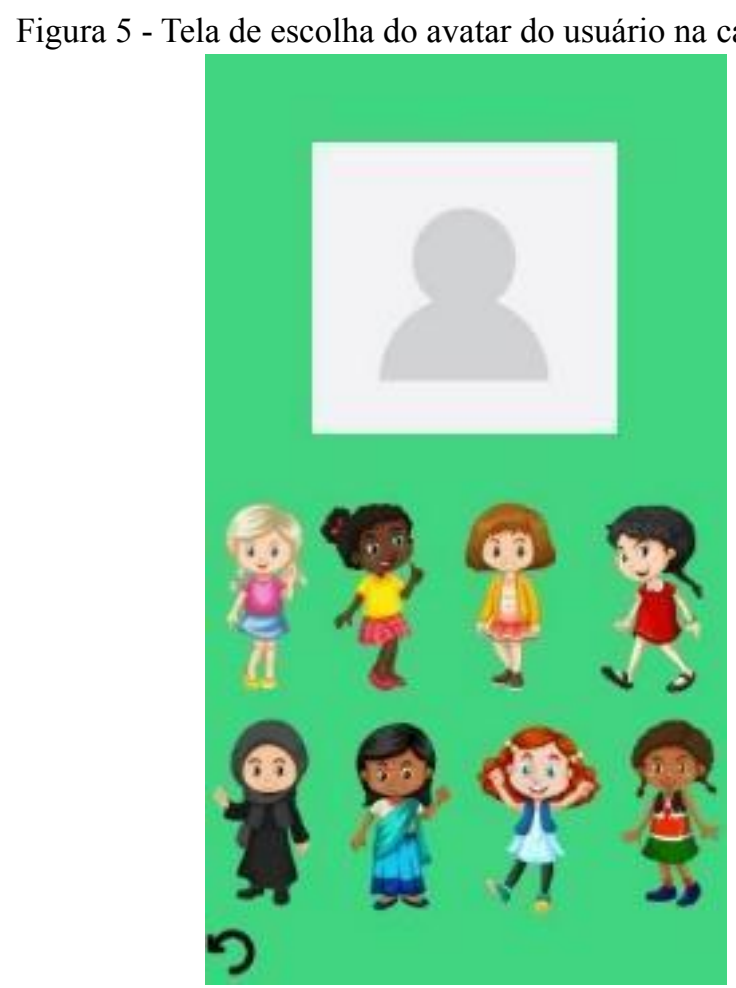

Fonte: Elaborado pelos autores, 2019.

Escolhida a foto, o usuário é encaminhado de volta para a tela principal, onde ele pode escolher a categoria de vocabulário que queria utilizar. Ao selecionar a categoria, o usuário será encaminhado para uma tela na qual existe um call for action para que seja aberta a câmera do aparelho móvel. Ao clicar no ícone de câmera da tela, a câmera do aparelho móvel será aberta para o que o usuário possa escanear, em seu livro impresso, um código QR disposto próximo a figuras e vocábulos pertencentes ao seu respectivo campo semântico, num sistema simples de acionamento remissivo com reconhecidas aplicações em práticas de mobile learning ou m-learning (VIEIRA; COUTINHO, 2013).

A Figura 6 mostra, à esquerda, um exemplo de tela de destino a que o usuário é remetido a partir do acionamento dos códigos QR para a categoria animals e, ao centro, a tela referente à leitura do vocábulo $\operatorname{dog}$ (cachorro), que pode ser acionada ao toque sobre a imagem alusiva a esse animal e que exibe uma figura ampliada do animal, o vocábulo escrito, uma frase simples de exemplo de uso do vocábulo e um botão acessar um vídeo. É possível 
notar, sobreposto à figura do cachorro, um ícone de call for action que, uma vez clicado, emite o som produzido por um cachorro, ou seja, um latido. Ao lado do elemento tipográfico dog há também um ícone de call for action, repetido ao lado da frase de exemplo. Ao clicar nos ícones descritos, o usuário terá acesso à pronúncia referente aos elementos textuais que aparecem na tela. Por fim, ao clicar no botão watch video, o usuário será encaminhado à tela seguinte, à direita na figura, onde é possível acionar a reprodução de um vídeo musical que explora essas representações do vocábulo em suas dimensões visuais e auditivas. Esse processo e disposição sequencial seriam repetidos para todas as demais categorias figuras.

Figura 6 - Tela de ilustrações vocabulares referentes à categoria animals, ao vocábulo dog e a seu vídeo

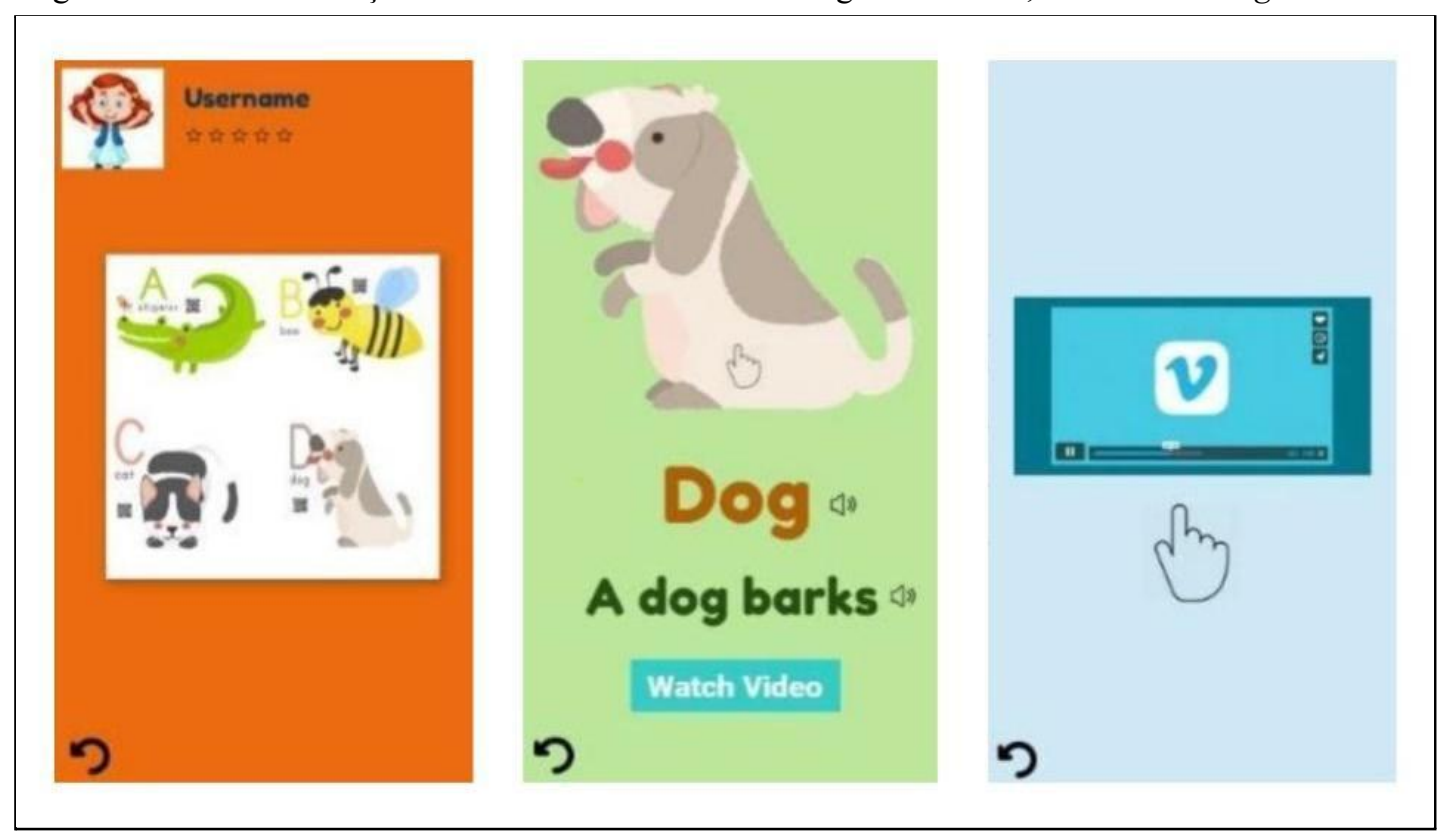

Fonte: Elaborado pelos autores, 2019.

Assim como o livro impresso, o conteúdo audiovisual não foi desenvolvido durante o trabalho de prototipagem, embora suas características básicas possam ser vislumbradas ainda nesse estágio, por exemplo, com a utilização de uma canção temática e a exibição de legendas com a letra que acompanha a música. Propõe-se que a plataforma de hospedagem para esses vídeos, uma vez desenvolvidos, seja o repositório Vimeo em sua versão profissional, que permite maior controle de permissionamento para acesso ao conteúdo.

Um fluxograma que ilustra a lógica de navegação de um aplicativo foi elaborado com uso da ferramenta Draw.io, de modo a demonstrar as relações de sequencialidade entre cada tela e os possíveis caminhos de navegação a serem tomados pelo usuário durante a utilização do aplicativo, instruindo, com isso, a arquitetura de informação a ser possivelmente adotada no desenvolvimento efetivo do produto digital ${ }^{9}$.

\subsection{Composição comercial do produto e modelo de distribuição}

A partir do que foi apresentado na seção anterior, é possível sintetizar a proposta de desenvolvimento do aplicativo VocAppulary, enquanto produto educacional original, a partir dos seguintes componentes midiáticos: (1) livro impresso e ilustrado (incluindo códigos QR)

\footnotetext{
${ }^{9}$ Caso a visualização do fluxograma seja de interesse do leitor do presente artigo, disponibilizamos o acesso pelo link https://drive.google.com/file/d/1nF_XWhR54ZY138JpjGBMT3ghFiwvmUkI/view?usp=sharing
} 
para aquisição de vocabulário de língua inglesa; (2) aplicativo digital para dispositivos móveis com conteúdo textual, imagético e audiovisual; e (3) série de vídeos e repositório externo para seu armazenamento e reprodução. Cada um desses componentes do produto implicaria um modo específico de acesso, distribuição e comercialização, conforme indicado no Quadro 2.

Quadro 2 - Fabricação e distribuição dos componentes do VocAppulary

\begin{tabular}{|c|c|c|}
\hline Componente & Fabricante & Distribuição \\
\hline Livro & Editora de livros paradidáticos & $\begin{array}{c}\text { Vendido em livrarias, escolas de } \\
\text { idiomas e lojas físicas e virtuais }\end{array}$ \\
\hline Aplicativo & $\begin{array}{c}\text { Software house (empresa de } \\
\text { desenvolvimento de sistemas) }\end{array}$ & $\begin{array}{c}\text { Download gratuito por meio de } \\
\text { lojas virtuais de aplicativos }\end{array}$ \\
\hline Vídeos & Produtora audiovisual & $\begin{array}{c}\text { Acesso restrito aos usuários } \\
\text { registrados para uso do aplicativo }\end{array}$ \\
\hline
\end{tabular}

Fonte: Elaborado pelos autores, 2020.

Dessa forma, a monetização do produto se daria através da venda do livro impresso paradidático. Uma vez que o aplicativo seria utilizável somente através da leitura dos códigos QR presentes no livro impresso, apenas os portadores do livro seriam especificamente motivados a acessar e fazer o download do app. O conteúdo audiovisual, por sua vez, teria acesso restrito a usuários do aplicativo, que seriam remetidos ao repositório de vídeos a partir do acionamento do botão específico disponível nas telas que ilustram cada vocábulo.

\section{Aplicabilidade do protótipo em contextos educacionais}

Uma vez prototipadas as configurações e funcionalidades do protótipo de aplicativo VocAppulary, foram consideradas suas possibilidades e condições de aplicabilidade em contextos educacionais. Uma vez que se trata de um protótipo, e não de um aplicativo já desenvolvido, não foram realizados testes práticos de aplicação junto ao público-alvo.

Entretanto, com o objetivo de compreender a validade e os limites da proposta, buscou-se conhecer, neste sentido, a visão de profissionais que atuam no ensino de língua inglesa para crianças. Para isso, um questionário semiestruturado foi aplicado junto a dois grupos de professores atuantes em duas escolas de idiomas de uma cidade no interior do estado de São Paulo: o primeiro composto por três professores de uma escola (sendo um deles também coordenador pedagógico) e o segundo, por sete professores de inglês de outra escola (sendo dois deles também coordenadores pedagógicos).

O questionário foi elaborado em versão online por meio da plataforma Google Forms ${ }^{10}$ e aplicado presencialmente aos dois grupos de professores após uma apresentação explicativa sobre as características e funcionalidades do protótipo. $\mathrm{O}$ questionário abordou a formação acadêmica e a prática didática dos educadores participantes e sua apreciação sobre os componentes principais do protótipo, incluindo elementos de design das telas, do conteúdo linguístico das atividades e, finalmente, da aplicabilidade desse produto para fins de educação. Os resultados dessa etapa do trabalho são apresentados na seção a seguir.

\footnotetext{
10 Versão PDF do questionário disponível em https://rive.google.com/file/d/11M3uL-SrUatKfMcUuXRw
} h0JG4f9R2gWB/view?usp=sharing acesso em 10 de março de 2020. 
5.1 Formação acadêmica dos educadores e sua relação com tecnologias digitais

A primeira seção do questionário abordou a formação acadêmica dos educadores e sua relação com elementos tecnológicos digitais. Dos dez professores, quatro participantes $(40 \%)$ são formados em Letras com licenciatura em Língua Inglesa e um participante (10\%) é formado em Letras com licenciatura em outra língua não especificada, quatro participantes $(40 \%)$ possuem formação em uma categoria assinalada como "outros cursos universitários" e um participante (10\%) não possui nenhuma formação acadêmica no ensino superior.

Sabe-se com isso, que metade dos educadores participantes do estudo (cinco) é licenciada em línguas estrangeiras e, portanto, pressupõe-se que eles tenham familiaridade com questões metodológicas de ordem pedagógica e didática, nos âmbitos teórico e prático. Como para o ensino de uma língua estrangeira em escolas de cursos livres o notório saber pode ser critério único para a contratação de professores, sendo estes dispensados de formação no ensino superior em cursos de licenciatura, é aceitável que a outra metade (cinco) seja composta por profissionais com outras formações.

Sobre o tempo de atuação como professores de inglês, cinco participantes $(50 \%)$ afirmaram possuir mais de dez anos de sala de aula, três participantes (30\%) disseram atuar como instrutores de ensino há menos de um ano, um participante (10\%) disse ter experiência com ensino do idioma por um período entre três e cinco anos, e um participante $(10 \%)$ afirmou atuar como professor por entre cinco e dez anos. Podemos notar por esses dados que o grupo de educadores mescla profissionais com experiência de pelo menos cinco anos e professores novatos que estão em seu primeiro ano de atuação docente.

De forma unânime, os professores responderam positivamente ao questionamento se trabalham ou já trabalharam com crianças em fase de alfabetização, o que mostra que o grupo de participantes possui pelo menos alguma experiência com alunos da faixa etária a qual se configura como público-alvo do protótipo de aplicativo VocAppulary.

Sobre a frequência com a qual os professores utilizam recursos tecnológicos em contextos educativos, eles responderam a três questões para as quais eles deveriam assinalar, em uma escala, valores que variam entre um (nunca) e cinco (sempre), conforme a escala Likert.

A primeira questão desta seção avalia a frequência com que utilizam recursos tecnológicos em sua prática docente e, para a qual, obtivemos os seguintes resultados, dispostos na Tabela 1 .

Tabela 1: Frequência de utilização de recursos tecnológicos na prática docente

\begin{tabular}{|c|c|c|}
\hline Valor & respondentes & Porcentagem \\
\hline $\mathbf{1}$ (nunca) & 0 & $0 \%$ \\
\hline $\mathbf{2}$ & 1 & $10 \%$ \\
\hline $\mathbf{3}$ & 2 & $20 \%$ \\
\hline $\mathbf{4}$ & 5 & $50 \%$ \\
\hline $\mathbf{5}$ (sempre) & 2 & $20 \%$ \\
\hline
\end{tabular}

Fonte: Elaborado pelos autores, 2020.

A segunda pergunta se referia à frequência na qual os professores usariam aplicativos para aparelhos móveis, especificamente, em sua prática docente. Obedecendo à mesma escala, chegamos aos seguintes resultados, os quais apresentamos, a seguir, na Tabela 2. 
Tabela 2: Frequência de utilização de aplicativos móveis na prática docente

\begin{tabular}{|c|c|c|}
\hline Valor & respondentes & Porcentagem \\
\hline $\mathbf{1}$ (nunca) & 1 & $10 \%$ \\
\hline $\mathbf{2}$ & 1 & $10 \%$ \\
\hline $\mathbf{3}$ & 3 & $30 \%$ \\
\hline $\mathbf{4}$ & 4 & $40 \%$ \\
\hline $\mathbf{5}$ (sempre) & 1 & $10 \%$ \\
\hline
\end{tabular}

Fonte: Elaborado pelos autores, 2020.

Finalmente, sobre esse tópico, os participantes responderam à terceira questão referente à frequência com a qual eles utilizam aplicativos para aparelhos móveis com fins de entretenimento. Os resultados obtidos se encontram dispostos na Tabela 3.

\begin{tabular}{|c|c|c|}
\multicolumn{2}{c}{ Tabela 3: Frequência de utilização de aplicativos móveis com fins de entretenimento } \\
\begin{tabular}{|c|c|c|}
\hline Valor & respondentes & Porcentagem \\
\hline $\mathbf{1}$ (nunca) & 1 & $10 \%$ \\
\hline $\mathbf{2}$ & 1 & $10 \%$ \\
\hline $\mathbf{3}$ & 3 & $30 \%$ \\
\hline $\mathbf{4}$ & 4 & $40 \%$ \\
\hline $\mathbf{5}$ (sempre) & 1 & $10 \%$ \\
\hline
\end{tabular}
\end{tabular}

Fonte: Elaborado pelos autores, 2020.

Por meio dessas questões, pudemos inferir sobre o nível de intimidade dos participantes com recursos tecnológicos, chegando à conclusão de que para as três perguntas, a maioria dos participantes atribuiu valores superiores ou iguais a quatro e cinco, apontando para a grande frequência do uso de recursos digitais.

A seção seguinte do questionário se referia à apresentação feita por um dos alunos pesquisadores, desenvolvedores deste trabalho. Os participantes atribuíram às duas afirmações, de forma unânime, o valor máximo da escala - novamente, foi utilizada escala de valores de um a cinco, desta vez um referindo-se a "discordo plenamente" e cinco a "concordo plenamente".

As afirmações eram as seguintes: "A partir da apresentação do protótipo, pude entender seu propósito e finalidade" e "A partir da apresentação do protótipo, pude entender seu funcionamento geral". A partir das respostas dadas pelos professores, notamos a uniforme afirmação que eles estavam plenamente cientes do funcionamento e propósito do protótipo ao passarem para a próxima seção do questionário que os inquiriu sobre os detalhes de configuração estética e de conteúdo do protótipo e suas possíveis aplicabilidades em contextos diversos.

Para melhor visualização dos dados e as questões que os tangem, apresentaremos trechos das questões semiabertas do questionário. Portanto, concordamos com a necessária subdivisão dos dados nas duas seções que se seguem. 
5.2 Avaliação das configurações do protótipo pelos professores participantes

Para esta seção, traremos trechos das respostas dadas às questões semiabertas do questionário. Para tanto, nomearemos os participantes como P1, P2, P3 e assim, sucessivamente. Vale salientar que tal nomenclatura foi atribuída de forma aleatória aos participantes, obedecendo, apenas, a ordem em que foram registradas suas contribuições na plataforma Google Forms. Os professores deveriam, novamente, atribuir valores de um (discordo plenamente) a cinco (concordo plenamente) às afirmações, além de justificar suas respostas por meio de comentários dissertativos.

A primeira seção de afirmações se concentrava nas questões sobre o layout e design do protótipo. Ao responderem a primeira afirmação que dizia a respeito à adequação das cores usadas ao público-alvo, nove participantes (90\%) assinalaram o valor máximo (cinco). Algumas das justificativas a essas respostas se encontram a seguir:

P2: As cores vivas chamam atenção das crianças.

P4: As cores são adequadas ao público infantil, pois são vivas e em sua maioria primárias.

Apenas um participante $(10 \%)$ assinalou valor quatro à afirmação em questão. Quando da justificativa, o professor apresentou o que se observa no seguinte trecho:

P7: O aplicativo tem a intenção de usar cores fortes e diversificadas em cada tela, a fim de chamar atenção do usuário final, que é uma criança. Porém, acredito que possa haver uma melhor concordância em relação aos tipos de cores selecionados e como combinar alguns padrões para que o aplicativo flua melhor aos olhos.

Ao se depararem com a afirmação "As fontes (tipos de letras) usadas no protótipo são adequadas à sua proposta e público-alvo", dez participantes (100\%) assinalaram "concordo plenamente". Um participante, no entanto, expôs em sua justificativa uma sugestão aos pesquisadores. Tal justificativa pode ser conferida no trecho a seguir:

P2: Apenas uma sugestão: uma fonte menos usual para melhor design do aplicativo. A já utilizada, apesar disso, atende sim ao público-alvo.

A próxima questão era relacionada às "figuras" utilizadas nas interfaces de tela do protótipo. Os participantes refletiram sobre a afirmação de que as figuras escolhidas pelos desenvolvedores do projeto estariam adequadas ao público-alvo. Mais uma vez, obtivemos $100 \%$ (dez participantes) de escolha ao valor máximo da escala utilizada. O mesmo foi observado quando os participantes refletiram sobre os "símbolo e ícones" presentes no projeto de prototipagem, ou seja, os dez participantes (100\%) assinalaram o valor máximo para o item.

A partir da leitura dos dados supracitados, é possível interpretá-los de forma que os educadores aprovaram a identidade visual no protótipo, no tocante às cores, figuras, símbolos e ícones, julgando-os adequados ao proposto público-alvo.

Avancemos, agora, à avaliação dos professores no que diz respeito ao conteúdo do protótipo de aplicativo VocAppulary. Assim como foi proposto anteriormente, os participantes deveriam concordar ou discordar de afirmações sobre o protótipo, além de justificar suas respostas de forma dissertativa. Sobre os componentes vocabulares presentes no projeto, tivemos, outra vez, atribuição unânime dos participantes (dez professores) ao valor 
correspondente a "concordo plenamente" quanto à adequação dos tais componentes ao público almejado.

Dispomos, a seguir, de algumas das justificativas a essa afirmação:

P8: Como o aplicativo é direcionado para as crianças em fase final de alfabetização, os componentes vocabulares são simples e adequados para essa faixa etária.

P9: Alunos praticamente alfabetizados se encantariam.

No que diz respeito à adequação das estruturas sintagmáticas presentes no protótipo, nos defrontamos com o mesmo nível de avaliação positiva, na qual $100 \%$ dos participantes atribuíram valor máximo ao tópico. Observamos no trecho, a seguir, o reconhecimento dos componentes sintáticos por um dos participantes e sua validação à estrutura como adequada a faixa etária do público-alvo.

P8: As estruturas sintagmáticas são adequadas e funcionais para o propósito do aplicativo. A sequência de um artigo, um substantivo e um verbo, é uma das mais efetivas para o aprendizado e o contexto da palavra nova que está sendo aprendida.

Um resultado diferente, porém, foi obtido na questão referente à adequação dos recursos multimodais - material impresso, áudio e vídeo, por exemplo. Dos dez participantes, oito $(80 \%)$ assinalaram que concordam plenamente com a afirmação sobre a adequação do tópico ao público-alvo, escolhendo o conceito cinco, e dois professores (20\%) assinalaram conceito quatro. Podemos observar os apontamentos dos educadores sobre o assunto, nas seguintes justificativas.

P8: Por ser multimodal, o uso pleno se torna mais restrito e específico para quem já tem conhecimento de aplicativos e plataformas digitais, mas nada que não possa ser resolvido com orientações claras de uso no próprio aplicativo e material impresso.

P9: É difícil dizer se esta criança iria gostar do uso do livro, porém a proposta é ousada e interessante

Podemos observar, nos trechos destacados acima, a ponderação de dois professores sobre a característica multimodal da nossa proposta. P8 reflete sobre como o nível de familiaridade do usuário com recursos tecnológicos digitais, como aplicativos e plataformas digitais, poderia influenciar no aproveitamento pleno do material, enquanto P9 considera a possibilidade de uma criança não gostar do uso do livro impresso. Entretanto, ambos os professores refletem sobre soluções e pontos positivos da proposta; P9 classifica o projeto como interessante e ousado, ao passo que P8 afirma que os possíveis percalços enfrentados pela falta de familiaridade com recursos digitais poderiam ser resolvidos com orientações presentes no aplicativo e livro, desde que de forma clara.

Satisfeitos com os resultados obtidos sobre o conteúdo do protótipo e sua adequação ao proposto público-alvo, na avaliação dos participantes, passaremos agora para a exposição e discussão dos dados referentes às possíveis aplicabilidades de um produto educacional que fosse, hipoteticamente, desenvolvido a partir de nossa proposta. 


\subsection{Aplicabilidade do aplicativo em contextos educacionais}

Após a apresentação e discussão dos dados que se relacionam às configurações do protótipo, passemos agora para a imprescindível discussão sobre a aplicabilidade da nossa proposta em contextos educacionais, na avaliação dos professores participantes da pesquisa.

$\mathrm{Na}$ última seção do questionário semiestruturado aplicado para o grupo de dez professores de língua inglesa, eles foram convidados a atribuírem conceitos de um ("discordo plenamente") a cinco ("concordo plenamente) e justificarem suas respostas, repetindo o processo realizado nas seções anteriores. Para tanto, os educadores se depararam com três afirmações; A primeira afirmação consistia em "um produto educacional desenvolvido com base neste protótipo pode ser utilizado em contexto de sala de aula". Todos os dez participantes $(100 \%)$ atribuíram valor máximo, concordando, portanto, plenamente com a declaração.

Destacamos, a seguir, trechos das justificativas dos professores às suas respostas:

P2: É uma ferramenta que pode auxiliar muito o professor ao mesmo tempo que entretém as crianças.

P6: Sim! Usaria com meus alunos para deixar a aula mais atrativa.

P7: Um produto desse tipo seria de extrema ajuda na sala de aula. $O$ aplicativo, junto ao livro, ajudaria crianças a interagirem melhor e prestarem mais atenção, trazendo melhores resultados. Essa interação tecnológica deixa um pouco a monotonia de lidar apenas com um livro e acrescenta algo mais interativo, deixando uma aula mais dinâmica.

P8: Com a orientação adequada e preparação prévia do professor, o uso desse protótipo na sala de aula se torna agradável e divertido para as crianças.

Podemos notar, através da leitura dos trechos destacados acima, que os professores têm visões positivas no que diz respeito ao possível uso de um aplicativo desenvolvido a partir de nossa proposta em suas salas de aula. O caráter lúdico da proposta é evidenciado nas falas dos educadores, podendo ser notado pelo uso dos verbos "entreter" e "interagir" e os adjetivos "atrativa", "dinâmica", "interativo", "agradável" e "divertido". De acordo com P2, o aplicativo auxiliaria o professor no processo de ensino, o que pode ter sido reiterado por P7, ao afirmar que o uso do aplicativo poderia, através da interação das crianças, trazer melhores resultados.

A segunda afirmação do questionário ("um produto educacional desenvolvido com base neste protótipo pode ser utilizado em contexto de sala de leitura ou biblioteca.") também obteve avaliações máximas de todos os dez participantes. Novamente, trazemos as falas dos professores, em destaque, para ilustrar suas justificativas.

P1: Sim, pode ser utilizado em sala de leitura ou biblioteca, podemos ter como uma ótima ferramenta.

P2: A criança pode até desenvolver interesse de permanecer em ambientes deste tipo com esse tipo de aplicativo.

P7: Dando sequência ao que foi dito, acredito que o fator tecnológico mesclado a forma clássica de leitura cria um balanço, deixando ambos os meios mais interessantes. 
É possível observar, pelos trechos destacados, que os professores avaliaram positivamente o uso do aplicativo no contexto de salas de leitura e biblioteca. Damos ênfase ao que foi dito por P2 e P7; o primeiro destaca que a utilização do aplicativo poderia ser um agente motivador para que crianças frequentassem tais tipos de ambientes, e o segundo ressalta que o sincretismo entre a tecnologia analógica do livro e a digital do aplicativo tornaria o produto mais interessante.

Apesar de todos os professores atribuírem valor máximo à declaração em questão, alguns deles demonstraram certa preocupação com a necessidade de uso de um dispositivo de saída de áudio no formato de fones de ouvido, para esses ambientes. Comprovamos esse fato através dos trechos destacados abaixo:

P3: Desde que seja utilizado com fones de ouvido para não atrapalhar outras pessoas.

P6: Sim! Os alunos teriam mais interesse em aprender, utilizando fones de ouvido.

P10: Somente se o aluno fizer uso de fones de ouvido.

Finalmente, quando em contato com a última proposição do questionário ("um produto educacional desenvolvido com base neste protótipo pode ser utilizado em contexto domiciliar."), nove dos dez professores (90\%) atribuíram valor cinco ("concordo plenamente") e um professor (10\%) atribuiu valor quatro. O participante que atribuiu esse valor justificou sua resposta com a seguinte reflexão:

P7: Em contexto domiciliar, seriam necessárias orientações mais profundas sobre seu uso, visto que nem todos os indivíduos possuem conhecimentos eletrônicos e de multiplataformas.

Acreditamos que o professor tenha refletido sobre a falta de um mediador qualificado, como a figura de um professor e/ou monitor, no ambiente domiciliar, o que poderia ser encontrado nos ambientes escolar e de sala de leitura e/ou biblioteca. Os pais ou responsáveis deveriam ter, a partir do que pode ser inferido da afirmação de P7, conhecimentos sobre recursos eletrônicos e plataformas multimodais.

\section{Considerações finais}

A partir da experiência de desenvolvimento e avaliação de um protótipo de produto educacional para dispositivos móveis, foi possível descrever, explorar e aplicar conceitos e atributos que caracterizam os recursos de mídia digital com potencial de uso educativo ou educacional, compreendendo suas características técnicas e estéticas, bem como os fatores que determinam sua proposta de valor e as condições para sua aplicação em contextos de educação formal ou não-formal, considerando aspectos de linguagem, design de informação, usabilidade, acessibilidade, entre outros.

Ao explorar formas, cores, animais e outros elementos representativos da experiência cognitiva de seu público-alvo, o conteúdo pedagógico proposto para o aplicativo VocAppulary corrobora a formulação de Bassano, Maillochon e Eme (1998) acerca dos recursos que conferem a crianças maior facilidade para a aprendizagem de palavras referentes a objetos quando estas podem ser relacionadas a ações. Por exemplo, "o cão late", o que, como visto, é ilustrado no produto digital prototipado com auxílio de recursos audiovisuais. 
Vale lembrar, a partir de Nation (2002), que a palavra é composta por três características básicas: a forma, o significado e o uso. O primeiro elemento remete à forma oral ou escrita e ortográfica; o segundo ao conceito, ou seja, o que a palavra significa; e o terceiro ao uso, que compreende a adequação da palavra a uma sentença ou situação, isto é, a um contexto de uso. Por isso, a associação de imagens a palavras é tão importante para sua aquisição em língua estrangeira. Para Cuadrado (1999, p. 9) [...] "há algo que na imagem não precisa ser ensinado, algo que resulta da prática da percepção, enquanto esta depende da maturação psicofisiológica e do processo natural de socialização".

Nesse contexto, o aplicativo proposto compreende ferramentas que possibilitam novas formas de se aprender a escrever, ler, ouvir e comunicar-se em língua inglesa durante a infância, levando as crianças usuárias desse recurso a aprender esse léxico de maneira também lúdica e interativa, usando o sincretismo das linguagens verbal, visual, gestual, sonora e imagética para favorecer a aprendizagem vocabular de uma língua estrangeira durante a infância, por meio de associações que lhe são intuitivamente acessíveis.

Por meio da aplicação do questionário semiestruturado a um grupo de dez professores de língua inglesa de duas escolas particulares de idiomas, também foi possível obter resultados que corroboram a hipótese de adequação de uso do produto idealizado para propósitos educacionais, tanto em ambiente escolar quanto domiciliar.

Por fim, a produção do protótipo em ambiente universitário também proporcionou a alunos de pós-graduação uma rara oportunidade de experimentação com processos de desenvolvimento de produtos de mídia digital, com efeitos positivos em sua formação acadêmica, ampliando seus horizontes científicos e profissionais.

\section{Referências}

BASSANO, D.; MAILLOCHON, I.; EME, E. Developmental changes and variability in the early léxicon: a study of French Children's naturalistic productions. Journal of Child Language, v. 25, n. 3, p. 493-531, 1998.

CUADRADO, C. Las Imágenes en La Clase de E/LE. Madrid: Edelsa, 1999.

FERRONATTO, B. C.; GOMES, E. Um caso de bilinguismo: a construção lexical, pragmática e semântica. Rev. CEFAC, São Paulo, v. 10, n. 1, 2008, p. 22- 28.

ALMEIDA JÚNIOR J. A.; OLIVEIRA R.N.R. Meu ABC Down: aplicativo para alfabetização e letramento de crianças com síndrome de down. CONEDU, 4., 2017. João Pessoa (PB) . [Anais]. João Pessoa (PB): CEMEP, 15 e 18 nov 2017. Disponível em: https://www.editorarealize.com.br/revistas/conedu/trabalhos/TRABALHO_EV073_MD1_SA 19_ID10036_16102017223010.pdf. Acesso em: 15 mar. 2020.

BEAUDOUIN, V. De la publication à la conversation: Lecture et écriture électroniques. Réseaux, n.116, p.199-225, 2002.

KRASHEN, S. D. Principles and practice in Second Language Acquisition. Oxford: Pergamon Press, 1982.

LEFFA, V.J.; VETROMILLE-CASTRO, R. Texto, hipertexto e interatividade. Revista de Estudos da Linguagem, v. 16, n. 2, p. 165-192, jul/dez 2008. 
LEMKE, J. L. Metamedia literacy: Transforming meanings and media. In.: REINKING, D.; MCKENNA, M.C.; LABBO, L. D.; KIEFFER, R. D. (ed.). Handbook of literacy and technology: Transformations in a post-typographic world. Mahwah, NJ: Erlbaum, 1998. p. 283-301.

LEVENTHAL, L. ZAJDENWERG, R.; SILVÉRIO, T. Inglês é 11. Barueri: Disal, 2007.

LEWIS, M. Pedagogical implications of the lexical approach. In J. Coady \& T. Huckin (ed.), Second language vocabulary acquisition: a rationale for pedagogy. Cambridge: Cambridge University Press, 1997. p. 255-270.

NATION, P. Learning Vocabulary in Another Language. Cambridge: Cambridge University Press, 2002.

PALALAS, A. Mobile-Assisted Language Learning: Designing for Your Students. In: THOUËSNY, S.; BRADLEY, L. (ed.) Second Language Teaching and Learning with Technology: Views of Emergent Researchers. Dublin: Research-publishing.net, p. 71-95, 2011. Disponível em: https://research-publishing.net/publication/978-1-908416-00-1.pdf. Acesso em: 15 mar. 2020.

ROJO, R. H. R. Multiletramentos na Escola. São Paulo: Parábola, 2012.

SAMPIERI, R. H.; COLLADO, C. F.; LUCIO, M. P. B. Metodología de la Investigación. 2.ed. México: Mac Graw Hill, 2006, p.736.

SCHÜTZ, R. Motivação e Desmotivação no Aprendizado de Línguas. English Made in Brazil, 2014. Disponível em https://www.sk.com.br/sk-motiv.html . Acesso em: 15 mar. 2020.

VIEIRA, L. S.; COUTINHO, C. P. Mobile learning: perspectivando o potencial dos códigos QR na educação. Universidade do Minho. Centro de Competência do Projeto Nónio Século XXI. 2013. Disponível em http://hdl.handle.net/1822/25450. Acesso em: 11 mar. 2020.

VIEIRA-ABRAHÃO, M. H. Metodologia na Investigação de Crenças. In: BARCELOS, A.M.F.; VIEIRA-ABRAHÃO, M.H. Crenças e ensino de línguas: foco no professor, no aluno e na formação de professores. Campinas: Pontes, 2006. p. 219-231.

Recebido em outubro de 2020.

Aprovado em maio de 2021. 